Research Article

\title{
Factors influencing the effect of locking plate fixation in proximal humeral fractures of the elderly
}

\author{
Kangquan Zhao ${ }^{1}$, Bin $\mathrm{Pi}^{1}$, Yimeng Wang ${ }^{1}$, Guoyang Wan ${ }^{1}$, Ji Shen ${ }^{2}$, Huilin Yang ${ }^{1}$ * \\ ${ }^{1}$ Department of Orthopedic Surgery, The First Affiliated Hospital of Soochow University, Suzhou, China \\ ${ }^{2}$ Department of Orthopedic, Shanghai Jiao Tong University, Affiliated Sixed People's Hospital, Shanghai, China
}

Received: 15 February 2016

Accepted: 31March 2016

*Correspondence:

Dr. Huilin Yang,

E-mail: yanghl_suda@163.com

Copyright: $\odot$ the author(s), publisher and licensee Medip Academy. This is an open-access article distributed under the terms of the Creative Commons Attribution Non-Commercial License, which permits unrestricted non-commercial use, distribution, and reproduction in any medium, provided the original work is properly cited.

\section{ABSTRACT}

Background: Curative effect following the locking plate fixation of proximal humeral fractures in the elderly have been inconsistent, factor that contributes to the outcomes remains unknown. This study aims to analyse the factors influencing the curative effect of locking plate fixation in proximal humeral fractures of the elderly.

Methods: A retrospective analysis was conducted for 72 elderly patients of proximal humeral fractures who had been treated from January 2010 to August 2013. Among the patients, 26 were male and 46 were female. The patients' age ranged from 60 years old to 78 years old, with an average age of 70.2 years. Constant score was used as clinical outcome measure. Gender, fracture type, plate position, varus of the head-shaft angle, associated injury, and the time to begin functional training after operation were identified as prognostic factors.

Results: The patients were followed up for 18 months to 48 months with a mean period of 30.4 months. The constant score ranged from 33 to 91 , with an average of 79.1. Shoulder joint function had a significant correlation with fracture type, plate position, and varus of the head-shaft angle. No significant difference was found between shoulder joint function and gender, associated injury, and the time to begin functional training after operation.

Conclusions: Fracture type, plate position, and varus of the head-shaft angle were key factors affecting the shoulder function after operation.

Keywords: Proximal humeral fractures, Locking plates, Influencing factors

\section{INTRODUCTION}

Among all kinds of fractures, $4 \%$ to $5 \%$ were proximal humeral fractures, which often happen to the elderly with osteoporosis. There is a growing concern about proximal humeral fractures of the elderly. ${ }^{1-5}$

Patients with undisplaced fractures often receive a good prognosis with conservative treatment, such as sling immobilization. However, locking plate fixation can lead to better results for patients with displaced or even comminuted fractures. ${ }^{6}$

Factors affecting the outcome of locking plate fixation remain controversial. This study evaluates both the functional and radiological outcomes after locking plate fixation to identify the key variables associated with clinical outcomes. Understanding the factors that affect post-operational outcomes could help improve therapeutic strategies and evaluate the prognosis for elderly patients with proximal humeral fractures.

\section{METHODS}

This retrospective study was approved by the ethics committee of Soochow University. We retrospectively reviewed the medical records of 83 patients who had proximal humeral fractures and underwent open reduction and internal fixation from January 2010 to August 2013. 


\section{Inclusion criteria}

- More than 60 years old,

- Treated with locking plate fixation,

- Primary healing of fracture.

\section{Exclusion criteria}

- $\quad$ Pathologic fracture (1 patient excluded),

- Incomplete radiographic or clinical data (4 patients excluded),

- Not enough follow-up (at least 18 months follow-up; 5 patients excluded),

- With other diseases that may affect the function of shoulder joint (1 patient excluded, scapulohumeral per arthritis on the same side of fracture).

After the exclusions, 72 patients were left. Of the 72 cases, 22 were caused by traffic accidents, and 40 were caused by falling.

\section{Surgical and rehabilitation procedure}

A deltopectoral approach was used to access the fracture. The tuberosity fragments were manipulated using sutures through the rotator cuff. The head fragment was reduced and temporarily fixed using Kirschner wires. The locking plate (AO philos) was used under fluoroscopy to confirm the reduction, position of the plate, and screw length. If metaphyseal defects were present, cancellous bone grafts were placed into the defect to promote fracture healing and to sustain reduction. All patients were hanging fixed of the operation arm and received anti-infection treatment and anti-osteoporosis treatment (vitamin D and calcium) postoperatively.

Functional training was initiated as soon as possible after surgery according to the reliability of internal fixation during the surgery and patients' tolerance for pain. Pendulum exercise (Patients stand and stoop, making the arm relax and fall naturally, then circle or swing the arm to extend the active range properly), active exercise of scapula in each plane and active exercise of neck in each plane were carried out in the first 2 weeks. A gradual increase in passive exercise of shoulder joint was carried out after 2 weeks. Hanging fixation was abandoned in the fourth week .Strength training was carried out gradually after 6 weeks.

\section{Assessment}

Preoperative X-ray and CT were inspected routinely. Follow-up visits were performed at 4 weeks, 3 months, 6 months, and 12 months postoperatively and annually thereafter. X-ray images were obtained at every follow up consultation to evaluate the plate position and the headshaft angle. Fracture type was classified according to the Neer's classification. A distance of $10 \mathrm{~mm}$ or less between the upper edge of the plate and the tuberosity was classified as a high plate position. ${ }^{7,8}$ Measurement of head-shaft angle shows in Figure 1 and a head-shaft angle of less than $120^{\circ}$ was regarded as an inversion. Constant score was used to assess shoulder function. Constant scores of $>85,71-85,56-70$, and $<56$ were rated as perfect, good, fair, and poor, respectively. ${ }^{9-10}$

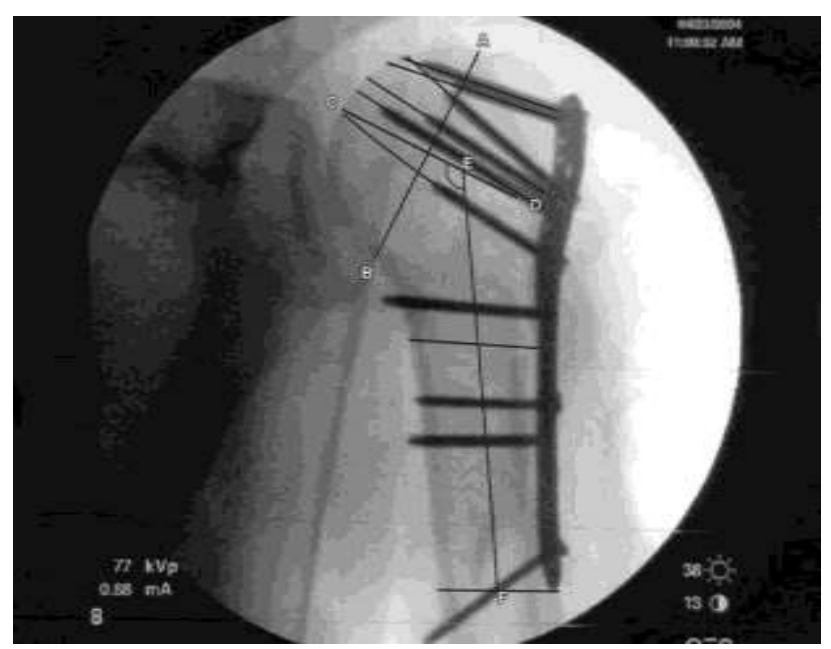

Figure 1: Measurement of head-shaft angle.

The head-shaft angle can be measured by drawing a line from the superior to the inferior border of the facies articular is (A-B line) .Then a vertical line to the A-B line through the center of A-B line ( $C-D$ line). The angle between the line bisecting the humeral shaft (E-F line) and the C-D line was measured as the head-shaft angle (semicircle).

\section{Statistical analysis}

SPSS 17.0 for Windows (SPSS Inc., Chicago, IL, USA) was used to analyze data. Gender, fracture type, associated injury, time to begin functional training, plate position, and varus of the head-shaft angle was set as independent variables. Constant score ratings of perfect and good were set as dependent variables. Independent samples t-test was conducted to determine significant difference about time between groups. The $\chi^{2}$ test was used to examine the outcome of all of the factors. The level of significance was set at 0.05 .

\section{RESULTS}

All 72 patients were available for follow up. The mean follow-up period was 30.4 months (18-48 months). The average Constant score was 79.1 points (33-91 points). Score were recorded as perfect in $22(30.6 \%)$, good in 26 $(36.1 \%)$, fair in $15(20.8 \%)$, and poor in $9(12.5 \%)$.

Among the patients, 26 were male and 46 were female, with ages ranging from 60 to 78 and an average age of 70.2 years. The types of fractures according to Neer's classification were as follows: 22 cases of two-part fracture, 31 cases of three-part fracture, and 19 cases of four-part fracture. ${ }^{7}$ Among three- or four-Part fracture, 9 
patients exhibited poor outcomes, whereas only 1 patient showed a poor outcome among those two-part fracture.

Twenty-two patients had associated injury, including 7 cases of fractures in other parts of the body, 14 cases of shoulder joint dislocation, and 1 case of axillary nerve injury. The perfect and good rating of patients with and without associated injury were $63.6 \%$ and $68.0 \%$, respectively, and this difference was not statistically significant $(\mathrm{P}=0.717)$.

Fifty-three patients began functional training within 3 days after operation, and 19 began functional training after 3 days. The mean time to begin functional training after operation of the 53 patients was 1.8 days, whereas the mean time to begin functional training after operation of the 19 patients was 6.6 days $(\mathrm{P}=0.025)$. Clinical outcomes of patients began functional training within 3 days after operation (perfect and good rating of Constant score, $64.2 \%$ ) and those after 3 days (perfect and good rating of Constant score , $73.7 \%$ ) showed no significant difference $(\mathrm{P}=0.449)$.
The perfect and good rating of patients with and without high plate position were $28.6 \%$ and $75.8 \%$, respectively, and this difference showed a statistically significant $(\mathrm{P}$ $=0.002$ ).

The mean head-shaft angle was $129.8^{\circ}$ (range, $116^{\circ}$ $138^{\circ}$ ) immediately postoperatively and decreased to $122.7^{\circ}$ (range, $113^{\circ}-137^{\circ}$ ) at the last follow-up. The perfect and good rating of patients who had a varus of the head-shaft angle was $30.0 \%$, whereas that of patients without a varus of the head-shaft angle was $75.4 \%$. This difference was statistically significant $(\mathrm{P}=0.002)$.

Table 1 shows the relationship between influencing factors and Constant's criteria, suggesting that shoulder joint function had a significant correlation with fracture type, plate position, and varus of the head-shaft angle. No significant correlation was found between shoulder joint function and gender, associated injury, and the time to begin functional training.

Table 1: Relationship between factors and the constant scores.

\begin{tabular}{|c|c|c|c|c|c|c|c|c|}
\hline \multirow[b]{2}{*}{ Factors } & \multirow[b]{2}{*}{$\begin{array}{l}\text { Number of } \\
\text { patients (n) }\end{array}$} & \multicolumn{5}{|c|}{ Constant score } & \multirow[b]{2}{*}{$\begin{array}{l}\chi^{2} \\
\text { value }\end{array}$} & \multirow[b]{2}{*}{$\begin{array}{l}\mathbf{P} \\
\text { value }\end{array}$} \\
\hline & & $\begin{array}{l}\text { Perfect } \\
\text { (n) }\end{array}$ & $\begin{array}{l}\text { Good } \\
\text { (n) }\end{array}$ & Fair (n) & $\begin{array}{l}\text { Poor } \\
\text { (n) }\end{array}$ & $\begin{array}{l}\text { Perfect }+ \text { good rating } \\
\text { percentage }(\%)\end{array}$ & & \\
\hline \multicolumn{9}{|l|}{ Gender } \\
\hline Male & 27 & 10 & 10 & 5 & 2 & 74.1 & \multirow{2}{*}{0.436} & \multirow{2}{*}{0.509} \\
\hline Female & 45 & 13 & 17 & 10 & 5 & 66.7 & & \\
\hline \multicolumn{9}{|l|}{ Fracture type } \\
\hline Two-part fracture & 22 & 12 & 8 & 1 & 1 & 90.9 & \multirow[b]{2}{*}{9.182} & \multirow[b]{2}{*}{0.002} \\
\hline $\begin{array}{l}\text { Three- Or four-part } \\
\text { fracture }\end{array}$ & 50 & 10 & 17 & 14 & 9 & 54.0 & & \\
\hline \multicolumn{9}{|l|}{ Associated Injury } \\
\hline Yes & 22 & 5 & 9 & 5 & 3 & 63.6 & \multirow{2}{*}{0.131} & \multirow[t]{2}{*}{0.717} \\
\hline No & 50 & 17 & 17 & 11 & 5 & 68.0 & & \\
\hline \multicolumn{9}{|c|}{ Time to begin functional training after operation } \\
\hline$\leq 3 \mathrm{~d}$ & 53 & 16 & 18 & 12 & 7 & 64.2 & \multirow{2}{*}{0.572} & \multirow{2}{*}{0.449} \\
\hline$>3 d$ & 19 & 7 & 7 & 3 & 2 & 73.7 & & \\
\hline \multicolumn{9}{|l|}{ High plate position } \\
\hline Yes & 14 & 2 & 2 & 9 & 1 & 28.6 & \multirow{2}{*}{9.321} & \multirow{2}{*}{0.002} \\
\hline No & 58 & 20 & 24 & 7 & 7 & 75.8 & & \\
\hline \multicolumn{9}{|c|}{ Varus of yhe head-shaft angle } \\
\hline Yes & 15 & 2 & 3 & 5 & 5 & 30.0 & \multirow{2}{*}{9.474} & \multirow{2}{*}{0.002} \\
\hline No & 57 & 21 & 22 & 10 & 4 & 75.4 & & \\
\hline
\end{tabular}

\section{DISCUSSION}

Treatment is difficult in elderly fracture patients with osteoporosis. Improper intraoperative reduction increases the risk of a second fracture, and pullout strength of screw decreased in osteoporotic bone, making the fixation unstable when using conventional plate. The use of locking plate for proximal humeral fractures is fast gaining popularity because of its better pullout strength and angle stability than conventional plates. ${ }^{11-14}$

We supposed several factors in this study that may affect the shoulder joint function after treatment, namely, gender, fracture type, associated injury, and time to begin 
functional training, plate position, and varus of the headshaft angle. Some of these factors were found to be significantly associated with shoulder joint function.

Studies have found that comminuted or displaced fractures often led to a poorer prognosis than simple or undisplaced fractures. ${ }^{15,16}$ The present study showed a significant correlation between Constant score and Neer's type of proximal humeral fractures, suggesting that fracture type was a possible factor to predict postoperative shoulder joint function. Compared with two-part proximal humeral fractures, three or four part fractures are usually caused by a greater force and a more complicated mechanism of injury. A considerable displacement leads to severe soft tissue injury, which has a negative impact on blood supply for healing and later functional training. Moreover, the occurrence of complications is closely related to the severity of the fracture. All of these factors result in poor shoulder joint function. ${ }^{17,18}$

The results of this study implied the importance of appropriate plate location for the favorable outcome of proximal humeral fractures. A significant correlation between constant score and plate location was observed. Patients with high plate positions achieved lower Constant scores than those with normal plate position, particularly in the active range of joint motion. Impingement syndrome is frequently seen as one of the common postoperative complications. Schliemann et al found impingement in $18.5 \%$ of the cases that they examined and raised that Impingement syndrome is closely related to improper plate position. ${ }^{18}$ Typically, when the shoulder joint is moved, the top of the plate may strike the shoulder peak and rostrum, hindering further motion of the joint. Anatomic locking plates provide several polydirectional locking holes at its attachment point to the humeral head, making it possible for comminuted and osteoporotic fractures to gain stability from a rigid fixation. Moreover, positioning the plate as low as possible provides enough space for shoulder joint activity.

Patients with varus of the head-shaft angle received lower perfect and good ratings than those without varus $(\mathrm{P}=$ 0.046). When the head-shaft is varus, the pullout strength of screw is not enough for the stability of fracture, especially in the elderly with osteoporosis. Feeble fixation aggravates the varus, thus, anatomical reduction is key to ensure long-term stability. Biomechanical studies have also shown the importance of reconstruction of head-shaft angle. ${ }^{19-21}$ Poor head-shaft angle reconstruction weakens the axial compressive strength, and axial compressive strength has a positive correlation with the degree of varus. A stable reduction and excellent function of shoulder joint depend on the quality of the reconstructed head-shaft angle. From our experience, large proximal humeral defects and poor reduction often cause varus of the head-shaft angle. Under these circumstances, Kirschner wire can be used to drill from the outside of the humerus head so that the position can be rectified according to the leverage.

No statistical significance in shoulder joint function was detected between male and female patients. We suspected that early functional training would effectively prevent articular adhesion and stiffness caused by a long period of fixation and that the existence of combined injury would affect opportunities for operation and functional training. However, the results showed that the two factors did not affect the outcome of proximal humeral fractures treated with locking plate fixation in the elderly. Statistical error because of the small sample was thought to be the possible cause of this unexpected finding.

\section{CONCLUSION}

This study showed that fracture type, plate position, and the varus of the head-shaft angle were key factors affecting shoulder function after locking plate fixation surgery. Knowledge of these key factors is beneficial for predicting the outcome of the operation and improving treatment. In clinical practice, thorough evaluation of patients according to fracture type as well as other possible factors, close attention to plate position and head-shaft angle reduction during the operation should improve the prognosis of shoulder joint function.

\section{ACKNOWLEDGEMENTS}

Thank the patients for willingness to participate. We acknowledge Dr. Xu Yang, Han Sun, Jiale Qian, Tao Feng, Lei Jiang, Wei Geng, Shenghao Wang, for their support by the conducting of this research.

Funding: No funding sources

Conflict of interest: None declared

Ethical approval: Not required

\section{REFERENCES}

1. Tamai K, Ishige N, Kuroda S, Ohno W, Itoh H, Hashiguchi $\mathrm{H}$ et al. Four-segment classification of proximal humeral fractures revisited: a multicenter study on 509 cases. J Shoulder Elbow Surg. 2009;18(6):845-50.

2. Rabi S, Evaniew N, Sprague SA, Bhandari M, Slobogean GP. Operative vs non-operative management of displaced proximal humeral fractures in the elderly: a systematic review and meta-analysis of randomized controlled trials. World J Orthop. 2015;6:838-46.

3. Muhm M, Bott J, Lahr C, Winkler H, Ruffing T. Outcome after operative treatment of proximal humeral fractures in elderly patients. Z Gerontol Geriatr. 2015.

4. Wong J, Newman JM, Gruson KI. Outcomes of intramedullary nailing for acute proximal humerus fractures: a systematic review. J Orthop Traumatol. 2015 . 
5. Chen H, Hu X, Tang H, Yang G, Xiang M. Minimal Invasive Percutaneous Osteosynthesis for Elderly Valgus Humeral Fractures with the PHILOS. Impacted Proximal. Biomed Res Int. 2015.

6. Chowdary U, Prasad H, Subramanyam PK. Outcome of locking compression plating for proximal humeral fractures: a prospective study. J Orthop Surg (Hong Kong). 2014;22:4-8.

7. Neer CS 2nd. Displaced proximal humeral fractures. I. Classification and evaluation. Journal Bone Joint Surg Am. 1970;52:1077-89.

8. Clavert P, Adam P, Bevort A, Bonnomet F, Kempf JF. Pitfalls and complications with locking plate for proximal humerus fracture. J Shoulder Elbow Surg. 2010;19:489-94.

9. Agudelo J, Schtirmann M, Stahel P, Helwig P, Morgan SJ, Zechel W et al. Analysis of efficacy and failure in proximal humems fractures treated with locking plates. Orthop Trauma. 2007;21:676-81.

10. Connstant CR, Murley AH. A clinical method of functional assessment of the shoulder. Clin Orthop Relat Res. 1987;(214):160-4.

11. Gaudelli C, Ménard J, Mutch J, Laflamme GY, Petit Y, Rouleau DM. Locking plate fixation provides superior fixation of humerus split type greater tuberosity fractures than tension bands and double row suture bridges. Clin Biomech (Bristol, Avon). 2014;29:1003-8.

12. Chiewchantanakit S, Tangsripong P. Locking plate fixation of proximal humeral fracture: minimally invasive vs. standard delto-pectoral approach. J Med Assoc Thai. 2015;98:196-200.

13. Königshausen $\mathrm{M}$, Thierbach A, Kübler L, Gessmann J, Godry H, Gothner M et al. Surgical treatment of 3- and 4-part fractures of the humeral head using a polyaxial-locking plate: results and patient satisfaction. Z Orthop Unfall. 2015;153:518.

14. Liu J, Di J, Zhao C, Yao S, Zhu L, Wang B, et al. Clinical efficacies of different internal fixation materials in the treatment of senile proximal humerus fractures. Zhonghua Yi Xue Za Zhi. 2014;94:3758-60.

15. Yang YS, Ma HT, Bi DW, Piao MS, Xu H. Treatment of proximal humeral fractures with percutaneous locking plate fixation through lateral deltoid approach. Zhongguo $\mathrm{Gu}$ Shang. 2014;27:244-7.

16. Clement ND, Duckworth AD, McQueen MM, Court-Brown CM. The outcome of proximal humeral fractures in the elderly: predictors of mortality and function. Bone Joint J. 2014;96:970-7.

17. Hussain S, Gul M, Dhar S. Open reduction and internal fixation of displaced proximal humerus fractures with AO stainless steel T-plate. Malays Orthop J. 2014;8:8-13.

18. Schliemann B, Siemoneit J, Theisen CH, Kösters C, Weimann A, Raschke MJ. Complex fractures of the proximal humerus in the elderly outcome and complications after locking plate fixation. Musculoskelet Surg. 2012;96(1):3-11.

19. Gardner MJ, Weil Y, Barker JU, Kelly BT, Helfet DL, Lorich DG. The importance of medial support in locked plating of proximal humems fractures. Orthop Trauma. 2007;21(3):185-91.

20. Zhang F, Zhu L, Yang D, Yang P, Ma J, Fu Q et al. Comparison between the spatial sub chondral support plate and the proximal humeral locking plate in the treatment of unstable proximal humeral fractures. Int Orthop. 2015.

21. Lescheid J, Zdero R, Shah S. The biomechanics of locked plating for repairing proximal humems fractures with or without medial cortical support. J Trauma. 2010;69:1235-42.

Cite this article as: Zhao $\mathrm{K}$, $\mathrm{Pi} \mathrm{B}$, Wang Y, Wan G, Shen J, Yang H. Factors influencing the effect of locking plate fixation in proximal humeral fractures of the elderly. Int Surg J 2016;3:812-6. 